\title{
South African private practising clinical dietitians' perceptions of the relevance of service-specific healthcare marketing principles and communication elements
}

Hanekom LM, Gericke GJ, MDietetics, Department Human Nutrition, University of Pretoria Becker PJ, PhD, Biostatistics Unit, Medical Research Council Correspondence to: Lizette Hanekom, e-mail: lizetteh@mailzone.co.za Keywords: marketing of dietetics profession, promotion of private practices

\section{Abstract}

Background: South African dietitians are confronted with the challenge of effectively marketing themselves as a sound source of information on nutrition to both the public and other health professionals. The marketing initiative should focus on the promotion of both the profession itself and individual practices. The aim was to assess the perception of South African private practising clinical dietitians of the relevance of service-specific healthcare marketing principles and communication elements (within the ambit of Act 53 of 1974). The design was a descriptive cross-sectional survey in the quantitative domain. Convenience sampling was used $(n=79)$.

Method: Data were collected by means of an electronic questionnaire. The response rate was low (16.8\%), and the results could not be generalised.

Results: The dietitians seemed more focused on the science of nutrition, than on marketing their profession and individual practices. There was an overall awareness of the need for marketing in the dietetic private sector, but the importance and implementation thereof did not receive the amount of attention that it justifies. A number of service-specific healthcare marketing principles received "slightly relevant" or "not relevant" ratings.

Conclusion: For the dietetic profession to reach its full potential in South Africa, and for dietetic private practices to be successful on all levels, dietitians need to focus more of their time and energy on business-related aspects such as marketing. By integrating the theory from the literature with the findings from the study, a profession-specific marketing flow diagram and recommendations could be proposed.

\section{Introduction}

According to Borra, "dietetics professionals are the public's leading sources of food and information on nutrition and services", and the overriding goal for the dietetic profession should be to increase the demand for dietetic services. ${ }^{1}$ Dietitians in clinical private practice are faced with the challenge of introducing themselves to the public as a source of sound scientific information on nutrition. They compete with the media and other less scientific sources. Therefore, considerable time, money, and expertise should be invested in marketing their profession and practice. ${ }^{2,3}$ Though many of these dietitians are professionally sound in their practices, often they do not have sufficient business skills, including marketing skills, to optimise the practice. ${ }^{4} \mathrm{~A}$ dietitian needs to have good business skills and strong self-assurance for the practice to be an overall success. ${ }^{4}$

The current status quo for private practising dietitians is as follows:

- As dietitians compete with many sources to supply the public with information on nutrition, marketing is essential for the promotion of both private practices and the dietetic profession in South Africa.

- The marketing of all healthcare services is legislatively controlled by the Health Professions Council of South Africa (HPCSA). All marketing efforts need to adhere to their guidelines.

- Knowledge, perception and attitudes influence the marketing approach followed by private practising dieticians.

- Guiding information on the marketing of products is easily available, and much simpler to implement than the marketing of services, especially professional services,

Therefore, it is essential for private practising dietitians to be aware of relevant marketing principles and communication elements such as direct marketing, client and public relations, advertising, and use of new technology [websites, cellular phone text messages (SMSs), CDs, and DVDs] when developing a marketing strategy. 
The aim was to assess the perception of private practising clinical South African dietitians of the relevance of service-specific healthcare marketing principles and communication elements. Their perception of service-specific characteristics was also determined, as well as a possible relationship between the biodemographic and practice-related information, and the involved marketing constructs respectively.

\section{Method}

The Faculty of Health Sciences Research Ethics Committee, University of Pretoria, approved the study (S32/2009). The research project was conducted in the quantitative domain, and was designed as a cross-sectional observational study.

In this study, qualitative data were measured via quantitative methods. $^{4}$

\section{Questionnaire development}

Limited research has been conducted on the marketing of private dietetic practices and no previous questionnaires could be found for the purpose of this study. Therefore, the researcher had to develop her own questionnaire by applying the literature to the reallife scenario. An expert group consisting of four private practising dietitians, a senior lecturer at the Department of Economic and Management Sciences of the University of Pretoria, and the study leader aided the process. The involvement of these people controlled the face and content validity of the questionnaire.

The questionnaire consisted of four sections (sections A-D). Section A was developed to gather bio-demographic and practice-related information about the study population. This type of information could be used to create a specific context for every individual respondent in which his/her data could be assessed. Section B was developed to determine the respondents' perception of the relevance of the specific characteristics of a service with regard to their own practice, or the practice for which they worked. These four characteristics were repeatedly discussed throughout the literature. ${ }^{6} \mathrm{~A}$ Likert scale was used throughout the questionnaire, and consisted of four options (scale points 1-4) to restrict the choice of a middle option. Section $\mathrm{C}$ was developed to determine the respondents' perception of the relevance of service-specific healthcare marketing principles with regard to their own practice, or the practice for which they worked. Section D contained two subsections. Specific communication elements were listed. Regardless of whether or not the respondents made use of it, they had to rate the perceived relevance of the element to the marketing of their own practice, or the practice for which they worked in the second subsection. The listed marketing communication elements were discussed comprehensively in a number of marketing textbooks. ${ }^{7}$

\section{Population and sample}

The target population consisted of 469 private practising dietitians, of whom 266 were employed in private practice full time, and 203 part-time, when the research study was carried out. The survey sample comprised voluntarily participating, registered, private practising clinical dietitians in South Africa, who were members of the Association for Dietetics in South Africa (ADSA). All dietitians received the survey information (measuring instrument) via e-mail. By completing and returning the questionnaire, they automatically gave informed consent to form part of the investigation.

\section{Data collection}

The self-administered questionnaire was sent to the target population via e-mail, as it is a convenient and cost-effective way of reaching participants nationally. ADSA was approached to aid in the sending of the e-mails, and the survey was attached to one of its weekly electronic newsletters. Although it was sent to everybody who was registered with ADSA, only the dietitians in clinical private practice were asked to complete and return the questionnaire to the researcher via e-mail. Comprehensive instructions were provided on completing and saving of the electronic questionnaire. As the response rate to an electronic questionnaire is perceived to be very low, ${ }^{5}$ several attempts were made to address this. Book incentives were offered, the return date was postponed, and random SMSs were sent to private practising dietitians, asking them to participate.

\section{Data analysis}

Data were captured by the researcher and double-checked to enhance reliability. Descriptive and inferential statistics (Kappa statistic and the Symmetry test) were used for the analysis.

\section{Description of sample}

Despite considerable effort, and an extension of the data-collection period, the response rate for the study was $16.8 \%$, and results could not be generalised. Response bias is a possibility, as some dietitians might have more interest in the business side and marketing of a practice than others, and might therefore have been more interested in participating in the study. The bio-demographic and practicerelated information of the sample is summarised in Table I.

\section{Results}

Services have four specific characteristics, namely intangibility, heterogeneity, inseparability and perishability. ${ }^{6}$ The respondents perceived three of the four characteristics to be "relevant", or "very relevant". The characteristic regarding intangibility was perceived to be "slightly relevant" by $34.62 \%$ of the respondents. No significant relationships between the bio-demographic and practice-related information, and the service-specific characteristics could be determined.

Inferential statistics were used to assess a possible relation between the respondents' perception of the service-specific characteristics, and their perception of the service-specific healthcare marketing principles. No significant relationships were found. With regard to their perception of the relevance of the service-specific healthcare 
Table I: Bio-demographic and practice-related information of respondents $(n=79)$

\section{Bio-demographic information}

\begin{tabular}{ll}
\hline Gender & Female: $99 \%$ \\
& Male: $1 \%$ \\
\hline Age & $<25$ years: $5 \%$ \\
& $25-34$ years: $53 \%$ \\
& $35-44$ years: $30 \%$ \\
& $45-54$ years: $12 \%$
\end{tabular}

Postgraduate qualification Postgraduate qualification: $65.38 \%$ No postgraduate qualification: $34.61 \%$

Business-related qualification Business-related qualification: $17.72 \%$ No business-related qualification: $82.28 \%$

\section{Practice-related information}

Period after studies before entering private practice

$<2$ years: $44 \%$ $2-5$ years: $24 \%$ 5- 10 years: $20 \%$ $\geq 10$ years: $12 \%$

Total number of years in private practice (permanently practising 2-5 years: $33 \%$

5-10 years: $22 \%$ $\geq 10$ years: $28 \%$

Total number of years in own private practice

$<2$ years: $19 \%$

$2-<5$ years: $29 \%$

$5-<10$ years: $23 \%$

$10+$ years: $25 \%$

N/A: $4 \%$

Monthly turnover: number of new patients in a good month

None: $2.53 \%$

1-20: $51.90 \%$

21-40: $27.85 \%$

41-60: $10.13 \%$

$\geq 60: 7.59 \%$

Monthly turnover: number of follow-up patients in a good month

None: $3.80 \%$

1-20: $39.24 \%$

$21-40: 17.72 \%$

41-60: $20.25 \%$

$\geq 60: 18.99 \%$ One or more dietitians in the
practice

Sharing of facility with other health professionals

Sharing with

Relation to medical group, e.g. Intercare or Medicross

Site of practice

Marketing
Single: $78.21 \%$

Multiple: $21.79 \%$

Sharing: $70.51 \%$

Not sharing: $29.49 \%$

Dietitians: $3.64 \%$

Doctors: $58.18 \%$

Physiotherapists: $40 \%$

Speech language therapists: $4.55 \%$ Occupational therapists: $12.73 \%$ Other: $65.45 \%$

Related: $16.4 \%$

Unrelated: $83.54 \%$

Urban: $87.17 \%$

Rural: $12.82 \%$

Own: $94.94 \%$

Contracted out: $1.27 \%$

Both: $3.80 \%$
Table II: Ranked list of service-specific healthcare marketing principles rated "very relevant" and "relevant"

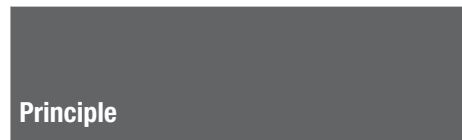

\begin{tabular}{c|c}
$\begin{array}{c}\text { "Very relevant" } \\
(\%)\end{array}$ & $\begin{array}{c}\text { "Relevant" } \\
(\%)\end{array}$ \\
(Likert point: 4) & (Likert point: 3)
\end{tabular}

1. The patient plays an important role

76.92 in the goals reached and success of (mode) the treatment.

2. The patient's needs should be met by clinical outcomes (goals reached) and level of support by the dietitian.

3. A service is evaluated by its tangible properties.

4. Patient loyalty as a result of long-term patient-service provider relationship is important for the success of the practice.

5. When patients miss an appointment, it impacts negatively on the finances of my practice.

6. Branding (providing a public image) for my dietetic practice is necessary.

7. A plan of action is essential to identify and rectify possible mistakes made or perceived.

8. The marketing management of a service differs from the marketing management of a product.

9. Patients (people who are referred) (mode) negative frame of mind than customers (people who came out of their own).

10. A patient's (somebody who is referred) expectation differs from a customer's (somebody who expectation with regard to my dietetic service. principles, they rated all the principles as either "relevant" (at a Likert scale point of 3), or "very relevant" (at a Likert scale point of 4). The principles are ranked according to their perceived relevance in Table II. These principles were compared to the practice-related information using the Kappa statistic. The latter is used to measure inter-rater agreement. When the practice-related information was compared with the service-specific healthcare principles separately, there was one significant tendency to rate Principle 4 [Branding (providing a public image) for my dietetic practice is necessary] more relevant, with an increase in the respondents' number of years in private practice $(p$-value $<0.05)$. There was no tendency to rate the specific principle more relevant when number of years in own private practice increased. 
Table III: Ranked list of marketing communication elements rated "very relevant" or "relevant" by the sample $(\mathrm{n}=79)$

\begin{tabular}{l|c|c}
$\begin{array}{l}\text { Communication } \\
\text { element }\end{array}$ & "Very relevant" (\%) & "Relevant" (\%) \\
(Likert point: 4) & (Likert point: 3)
\end{tabular}

\section{Personal marketing (client and public relations)}

\begin{tabular}{|c|c|c|}
\hline Group $1^{\mathrm{a}}$ & 77.2 (mode) & 20.25 \\
\hline Group $2^{\mathrm{b}}$ & 79.10 (mode) & 20.90
\end{tabular}

\section{Personal marketing (direct marketing)}

\begin{tabular}{|l|l|l|}
\hline Group 1 & 58.23 (mode) & 27.85 \\
\hline Group 2 & 63.49 (mode) & 26.98 \\
\hline
\end{tabular}

\section{Advertising}

\begin{tabular}{|l|l|l|}
\hline Group 1 & 30.38 & 45.57 (mode) \\
\hline Group 2 & 40.35 & 47.37 (mode)
\end{tabular}

40.35

40.51 (mode)

Group 1

26.58

48.15 (mode)

Group 2

33.33

5. New media marketing (cellular technology and SMSs)

\begin{tabular}{|l|l|l|}
\hline Group 1 & 24.05 & 39.24 (mode) \\
\hline Group 2 & 37.50 & 47.50 (mode)
\end{tabular}

6. Sponsorship

\begin{tabular}{|l|l|l|}
\hline Group 1 & 18.99 & 44.30 (mode) \\
\hline Group 2 & 25.00 & 57.50 (mode)
\end{tabular}

7. New media marketing (interactive website)

\begin{tabular}{|l|l|l|}
\hline Group 1 & 22.78 & 32.91 (mode)
\end{tabular}

\begin{tabular}{l|l|l} 
Group 2 & 37.50 (mode) & 25.00
\end{tabular}

8. New media marketing (CD and DVD technology)

\begin{tabular}{|c|c|c|}
\hline Group 1 & 8.86 & 20.25 \\
\hline Group 2 & 28.57 & 42.86 (mode)
\end{tabular}

9. Sales promotion (free handouts)

\begin{tabular}{|l|c|c|}
\hline Group 1 & 5.06 & 13.92 \\
\hline Group 2 & 16.67 & 33.33 \\
\hline
\end{tabular}

10. Publicity

Group 1

3.80

11.39

Group 2

11. Sales promotion (incentives)

Group 1

2.53

11.39

Group 2

57.14 (mode)

$a=$ Those who responded, irrespective of whether or not they used the communication element $b=$ Those who used the communication element

Respondents' perceptions of the relevance of specific marketing communication elements were assessed. Regardless of whether or not they used the element, all elements were perceived to be "relevant" or "very relevant", except for two: free handouts were perceived to be only "slightly relevant", and incentives were perceived to be "not relevant at all". A ranked list of the perceived relevance of these elements is given in Table III.

\section{Discussion}

Three of the four characteristics (variability in service delivery, client involvement, and number restrictions on patients) had a majority rating of either "relevant", or "very relevant". It might be possible that dietitians had a better understanding of these three characteristics than the first one (pertaining to intangibility), as they are more directly confronted with them in private practice. ${ }^{8}$ Without any additional business qualification, they would be aware of these characteristics, whereas intangibility is a complex concept that requires some extra thought. ${ }^{8}$ The realisation that the success of the consultation depends solely on the attitude and cooperation of the patient was clearly reflected in the results of this section. The two highest-ranked principles support this view.

For the first four principles in Table II, the mode was in the "very relevant" column. It supported the perceived relevance of client or patient satisfaction, as these four principles relate directly to the former. For each of the remaining principles, the mode lies within the "relevant" column. The questionnaire was developed with four rating options in order to prevent the respondents from choosing the middle option all the time. Although this preventative measure was taken, it was observed that in general, some respondents marked the "relevant" options on the questionnaire. There is no way of clarifying the marked options, but the possibility of bias should be kept in mind when interpreting the results.

Principles 5 to 8 focus on marketing from a business point of view, rather than from a client-motivated view. Although the client or patient is still mentioned, the emphasis is on marketing as a managerial function. The mode for all these principles lies within the "relevant" column. According to the literature, these are very relevant principles with regard to the marketing of any health profession. ${ }^{9}$ It might be that dietitians place less emphasis on the business side of the practice than the dietetic and technical aspect, and that they have not had formal training in management and marketing. ${ }^{10}$ The findings are in agreement with the literature, where the marketing approach of a professional service pivots around the relationship approach, in which the satisfaction of the client plays an integral role. ${ }^{11,12}$ Although the abovementioned aspect is of the utmost importance in the success of a dietetic practice, more attention needs to be paid to the business and to marketing principles, because dietetic practices compete with other sources of information on nutrition that are managed from a business point of view. According to Kapica and 0'Sullivan Mallet, "to perform optimally in any field of dietetics, some knowledge of business practices is required". ${ }^{13}$

When the relevance of the marketing communication elements was assessed, the respondents were divided into two groups (refer to Table III). Group 1 consisted of those respondents who had, or had not used, the element before, and Group 2 consisted of only those respondents who had used the element before. The findings from Group 1 were used for the ranking of the elements, as this was the largest group. 
The two personal marketing elements (direct marketing and client and public relations) were rated "very relevant" by the majority of the respondents. The "very relevant" option was also the mode for both groups. It supports the results from the previous sections, where the strong client focus was apparent. These findings might be attributed to the formal training of dietitians as health professionals, during which they learn to focus on the needs of patients and clients. ${ }^{14}$

The third communication element in the ranking was advertising, and the mode for both groups was the "relevant" option. This form of marketing is well known and used by many people, even those without formal business training. Advertising is followed by new media marketing, via website and cellular technology such as SMSs. This finding reflected positively on the mindset and attitude of dietitians. By making use of new media marketing, and keeping up to date with technological trends, the dietitians displayed a strong business orientation, essential for the success of a private practice. This means that they accept technological progression and change, and also have an open mind to new ideas and research that would benefit their patients. ${ }^{15,16}$

The last communication element that had the same mode (a Likert scale point of 3) for both groups was sponsorship. Sponsorship usually relates to larger businesses with a bigger income turnover. ${ }^{17}$ In this study, the focus was on the dietitian as sponsor. According to the literature, the roles can be reversed with a positive outcome. An industry sponsorship can benefit a dietetic practice. Industry sponsorship allows for the expansion of the scope and depth of projects, services and communications. ${ }^{17}$

For the last five elements, the mode differed between Group 1 and Group 2. An interactive website was mostly rated "very relevant" by Group 2. It can be concluded that the majority of the respondents rated the element "relevant", if not "very relevant". New media marketing, in the form of CD and DVD technology, was rated either "relevant" or "very relevant" by Group 2 (those who have used the element before) in contrast with the ratings of Group 1, where the majority rating was within the "slightly relevant" group (not shown in the table).

The mode for the communication element (sales promotion in the form of free handouts) was the "slightly relevant" option (at a Likert point of 2) for both Groups 1 and 2 (not shown in the table). Literature regarding to the practical implementation of this element in the dietetic profession is limited. The same finding was reported for the publicity element. This particular response was not expected. The literature emphasises the opportunities that might evolve for private practices when nutrition-related topics receive publicity. ${ }^{18}$ Either the respondents did not understand the question, or they did not realise that general nutrition publicity should be viewed as a passive marketing tool. ${ }^{18}$ The publicity that certain nutrition topics receive relates to the needs of the general public. By being aware of topics addressed in the media, dietitians can customise their practice to fill the gap, and thereby generate more business..$^{18}$ Incentives were rated "relevant" by Group 2 and "not relevant" by Group 1. Possibly, those in Group 1 were concerned about the ethical implication of incentives. If done within ethical guidelines, incentives can contribute to the motivation of the patient, as indicated by the rating of Group 2. The findings are in accordance with the client-focused approach, as has been highlighted throughout the study. Dietitians need to focus more on the business-orientated approach. The possibility also exists that they restrict themselves when deciding on marketing communication elements because they are not always fully aware of what is, and what is not, allowed by legislation. ${ }^{8}$

The theory from the literature and the findings from the study are summarised in a flow diagram consisting of constants and variables (refer to Figure 1). It is a dynamic flow diagram, and can be adjusted over time to account for a change in variables. The variables are the service-specific healthcare marketing principles and the marketing communication elements. These variables can change over time as progression takes place, whether this progression is economic, legislative, political, professional or personal in nature. The servicespecific characteristics, service-specific healthcare marketing principles and marketing communication elements are indicated in a ranked order, where, currently, the top one is perceived to be the "most relevant" by dietitians in South Africa. This order might also change, and should be reassessed from time to time to remain relevant.

The constants are identified in the literature, and although new constants might be added in future, the old ones should still remain. The constants, namely financial resources, legislation, training, and personality, influence a dietician's attitude towards, and perception of, the marketing approach.

The constants can be explained as follows:

- Financial resources: Financial resources directly affect the choices a dietitian makes with regard to the management of his or her practice, and the risks that he or she takes. ${ }^{10}$

- Legislation: Legislation pertains to the marketing guidelines of healthcare professionals as stipulated by the HPCSA. ${ }^{19}$

- Training: Training of any sort, whether it is dietitian undergraduate course material or additional business courses, has an effect on a dietitian's attitude towards, and perception of, the marketing approach. ${ }^{20}$

- Personality: Personality affects a person's willingness to take risks, and indirectly has an influence on a dietitian's attitude about marketing. ${ }^{10}$

Perceptions about service characteristics and service-specific healthcare marketing principles also influence views on the marketing approach. The marketing approach determines marketing strategy, which, in turn, leads to use of specific marketing communication elements. The rank order of these elements can be changed, or over time, some of them can be substituted. Although the framework remains the same, the model's variables should be determined by regularly repeating the study to ensure relevance and applicability to 


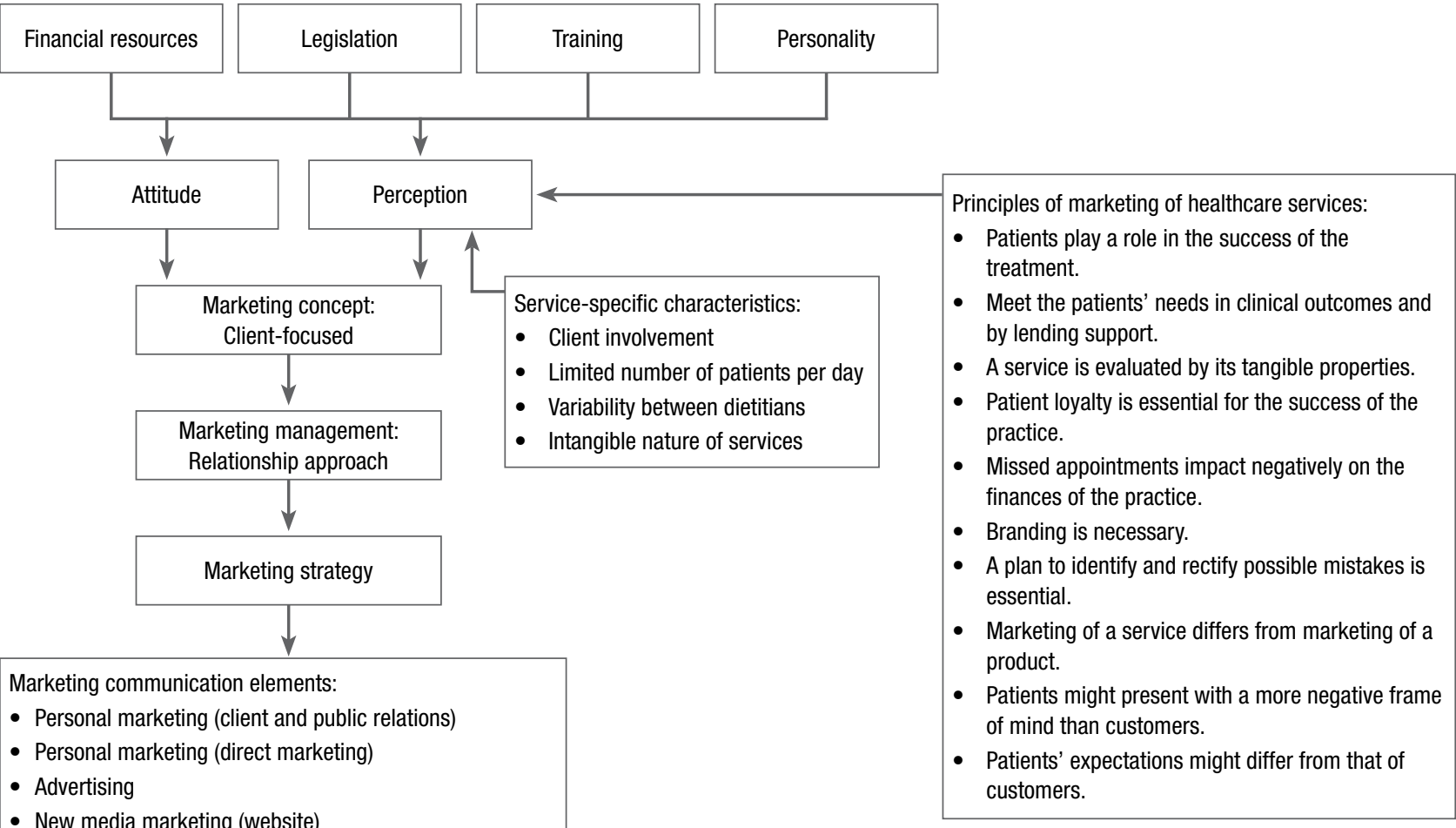

- New media marketing (website)

- New media marketing (cellular technology and SMSs)

- Sponsorship

- New media marketing (interactive website)

- New media marketing (CD and DVD technology)

- Sales promotion (free handouts)

- Publicity

- Sales promotion (incentives)

Figure 1: Flow diagram for the marketing of private clinical dietetic practices in South Africa

the South African scenario. The proposed flow diagram parallels that of the Nine Steps for Marketing of Dietetic Services, as published by the Dietetics Association of Australia. ${ }^{21}$

Taking into consideration the South African-specific flow diagram, and the aforementioned Australian guidelines, practical recommendations to guide South African private practising dietitians to market their practices are summarised in Table IV.

\section{Conclusion}

In 2008, the American Dietetic Association (ADA) stated the following: "Management skills are integral to success, in an increasingly complex dietetics profession". ${ }^{22}$ Not only do good management skills contribute to the promotion of dietetics as a profession, they are also essential for dietitians in private practice. Management is a complex subject, and has many components. Because of the complexity of this subject, only one of its components was addressed in this study. As dietitians are confronted with many challenges when marketing themselves, their practices and their profession, in this study, attention was paid to marketing as one aspect of several managerial functions.
The marketing of South African clinical dietetic practices is challenging because of many influencing factors, including legislation, financial resources, training and personality (refer to Figure 1 for a comprehensive integration). The study aimed to determine the perceived relevance of different marketing characteristics, principles and elements. The findings were combined with theory from the literature to propose a flow diagram (Figure 1) for the marketing of dietetic practices in South Africa. An apparent finding was that dietitians have a strong client focus. This can be very beneficial for the overall marketing of the practice, but only if it is applied correctly through the marketing plan. Although client focus is of the utmost importance, it should not be the only aspect to which attention is given, and should be approached from many different angles. Client focus does not only pertain to the physical consultation scenario. By using the correct communication elements, a dietitian can meet the needs of a potential client, and by devising a plan of action to rectify possible mistakes, a dietition can address the needs of a disappointed or angry patient. Therefore, although it is a very important principle in the marketing of practices, client focus should be in balance with other principles that place emphasis on the service itself. 
Table IV: Practical recommendations for the marketing of South African private practising dietitians' practices

Steps to follow when marketing a dietetic practice

Step 1: Think it through

Step 2: Construct a formal marketing plan ${ }^{21}$

Step 3: Effectively communicate with the public and other healthcare professionals ${ }^{2}$

Step 4: Reassess and revise with an open mind

\section{Explanation of different steps}

Before a marketing plan can be compiled, the following must be considered:

- Legislation with regard to marketing of the profession.

- Knowledge and perceptions about marketing, and how to improve it, if necessary.

- Purpose and objectives of the private practice.

- Target market (including market research). ${ }^{21}$

- Personality type to identify what will work best for you.

- Available financial resources.

Compile a formal marketing plan based on the relationship approach. Keep in mind the important role that the patient or client plays in the success of the treatment. His or her needs should be met by the clinical outcomes. Marketing is a continuous process that includes the periods before, during, and after a consultation. This plan should include the communication strategy (consisting of appropriate communication elements), ways to make the consultation more tangible, and an evaluation tool to be used afterwards. ${ }^{21}$

Different communication elements can be used to market the practice. At present, the most relevant ones in South Africa seem to be personal marketing, conducted through client or public relations, and direct marketing, i.e. one-to-one discussions with other healthcare practitioners, or word-of-mouth among clients. Advertising, through the use of pamphlets, posters and personalised stationery, is a non-personal marketing technique, and is also rated as relevant. General visibility can be improved through partnerships. ${ }^{21}$

The marketing plan should be reassessed and revised on a regular basis to maintain a competitive edge, and to accommodate the changing expectations of the healthcare consumer.
A business-orientated mindset is necessary for the successful marketing of a dietetic practice. Dietitians tend to focus more on the science of nutrition, than on the business side of their practices or on the promotion of the profession. As a result, the success of the practice and the efficacy of dietitians in South Africa might be compromised. This gap needs to be closed in order to optimise growth of the profession and the personal practice. It does not necessarily mean that dietitians should become marketers themselves, but they should be aware of the importance of marketing as a managerial function. If they do not want to invest time and energy in marketing, they should make use of contract marketers. The baseline should always be the same for all dietitians. They have a responsibility towards their colleagues. This entails marketing themselves in a such a way that the profession is promoted. Projecting a negative image of themselves and their competencies might harm the overall image of South African dietitians. By positively branding dietitians in South Africa, the success of private practices is enhanced, while authority is conferred on dietitians as nutrition experts. More work opportunities are also created.

\section{Acknowledgements}

Acknowledgement is given to the Association for Dietetics in South Africa for a supportive research grant.

\section{References}

1. Borra T. Promoting our profession. J Am Diet Assoc. 2001;101(7):732.

2. Borra T, Earl R, Hogan E. Paucity of nutrition and food safety 'news you can use' reveals opportunity for dietetics practitioners. J Am Diet Assoc. 1998;98(2):190-193.

3. Peregrin T. Branding ADA starts with Y-0-U. J Am Diet Assoc. 2008:108(6):928.

4. Brown D. Unique careers for dietetics professionals. J Am Diet Assoc.2005;105(9):1358-1360

5. Leedy PD, Omrod JE. Practical research: planning and design. $7^{\text {th }}$ ed. New-Jersey: Prentice Hall; 2001.

6. Jordaan Y, Prinsloo M. Grasping service marketing. $2^{\text {nd }}$ ed. Pretoria: Grapevine News; 2004.

7. Bennet JA, Niemand G. Business management. Pretoria: Van Schaik; 2002.

8. Du Toit T, Leach M, Meiring C, Scharff S. Personal communication: private practising dietitian expert group; 2008.

9. Christopher L, Corbin SW, Kelly RWS. Concepts in service marketing for healthcare professionals. Am J Surg. 2001;181(1):1-7.

10. Cluskey M, Gerald M, Gregoire M. Management in dietetics: are we prepared for the future? J Am Diet Assoc. 2007;107(3):386-389.

11. Gronroos C. Relationship approach to marketing in service contexts: The marketing and organizational behavior interface. J Bus Res. 1990;20(1):3-11.

12. Gelb BD, Gelb GM, Smith SV. Service marketing lessons from the professionals. Bus Horiz. 1988;10:29-34.

13. Kapica C, O'Sullivan Mallet J. A business rotation for dietitians: an imperative in the new millennium. $J$ Am Diet Assoc 2002;102(9):1220.

14. Health Professions Council of South Africa. Regulations defining the scope of the profession of dietetics;

15. Peregrin T. Business plan 2.0: Putting technology to work. J Am Diet Assoc. 2008;108(5):S24-S26

16. Dodd JL. Look before you leap - but do leap! J Am Diet Assoc. 1999:99(4):422-425.

17. Feeney MJ, White JV. Corporate alliances: a strategy for success. J Am Diet Assoc. 2000;100(10):1124.

18. McMarnamon B, Pazder N. Pitching your ideas to the media. J Am Diet Assoc. 2000;100(12):1451-1453.

19. Health Professions Council of South Africa. Guidelines for making professional services known; 2001.

20. Dowling R. Role expansion for dietetics professionals. J Am Diet Assoc. 1996;96(10):1001-1002.

21. Burton S, Freeman J. Marketing the dietetics profession to consumers and stakeholders: a social and professional imperative. Nutr Diet. 2005;62(4):158-160.

22. Canter D, Gould RA. Management matters. J Am Diet Assoc. 2008;108(11):1834-1836. 